\title{
PEDOGÊNESE DE PLANOSSOLOS EM TOPOSSEQUÊNCIA DO AGRESTE PERNAMBUCANO ${ }^{(1)}$
}

\author{
Roberto da Boa Viagem Parahyba ${ }^{(2)}$, Mauro Carneiro dos $\operatorname{Santos}^{(3)}$, \\ Fernando Cartaxo Rolim Neto ${ }^{(4)}$ \& Paulo Klinger Tito Jacomine ${ }^{(5)}$
}

\begin{abstract}
RESUMO
Os Planossolos assumem, na região do Agreste do Estado de Pernambuco, grande importância econômica, tanto pela sua magnitude de ocupação quanto pela utilização intensiva, especialmente com atividades agropecuárias. Aspectos como dualidade ou retrabalhamento do material de origem e natureza dos processos envolvidos na formação das marcantes diferenciações texturais e nas concentrações de $\mathrm{Na}$ e de sais são pontos importantes a serem esclarecidos. Este trabalho teve como objetivo avaliar o processo de pedogênese dos Planossolos no Agreste de Pernambuco, com base nos resultados das análises físicas, químicas, mineralógicas, macromorfológicas e, especialmente, micromorfológicas. Foram estudados três perfis de solos com marcante contraste textural, em trincheiras abertas ao longo de uma topossequência de solos. Realizaram-se análises físicas, químicas, mineralógicas e macro e micromorfológicas. Verificou-se que os solos são autóctones e que os nítidos contrastes texturais, devido à argilização dos horizontes Bt, parecem ser, principalmente, o resultado de uma combinação de processos e não uma simples eluviação-iluviação (lessivagem). Entre esses processos estão incluídos a intemperização de biotitas, com formação in situ de argilas, e as perdas dessa fração, devido a movimentações laterais por arraste mecânico ou dissoluções. A combinação exata desses processos, bem como a acumulação de $\mathrm{Na}$, foi fortemente influenciada pelo posicionamento dos solos no relevo.
\end{abstract}

Termos de indexação: horizonte Bt plânico, micromorfologia, intemperismo de biotita.

\footnotetext{
(1) Parte da Tese de Mestrado do primeiro autor. Recebido para publicação em dezembro de 2009 e aprovado em outubro de 2010.

(2) Pesquisador da Unidade de Execução de Pesquisa do Recife/Centro Nacional de Pesquisa de Solos - EMBRAPA. Rua Antônio Falcão 402, Boa Viagem, CEP 51020-240 Recife (PE). E-mail: parahyba@uep.cnps.embrapa.br

(3) Professor Adjunto aposentado, Departamento de Agronomia, Universidade Federal Rural de Pernambuco - UFRPE. Rua Dom Manoel de Medeiros s/n, Dois Irmãos, CEP 52171-900 Recife (PE). E-mail: mcs@terra.com.br

(4) Professor Associado, Departamento de Tecnologia Rural, UFRPE. E-mail: fcartaxo@dtr.ufrpe.br

(5) Professor Sênior, Departamento de Tecnologia Rural, UFRPE. E-mail:pauloklinger@hotmail.com
} 


\title{
SUMMARY: PEDOGENESIS OF PLANOSOLS IN A TOPOSEQUENCE OF THE AGRESTE REGION OF PERNAMBUCO, BRAZIL
}

\begin{abstract}
In the Agreste region of Pernambuco state, Planosols are economically highly important, due to the degree of occupation, as well as the heavy use, mainly for agricultural activities. Aspects such as duality or reworking of parent material, which characterize the processes involved in the formation of the marked textural differences and of Na and salt concentrations, are important points to be clarified. This study aimed to evaluate the pedogenetic process of the Planosols in the region Agreste, state of Pernambuco, based on physical, chemical, mineralogical, macromorphological, and especially micromorphological data. Three soil profiles with marked textural contrast were studied, in trenches opened along a soil toposequence. Physical, chemical, mineralogical, and macro and micromorphological analyses were performed. The soils were found to be autochthonous and the sharp textural contrasts due to argilic Bt horizons seem to be mainly the result of a combination of processes and not simply Elution-illuviation. The processes include the weathering of biotite, forming in situ clay fraction, and losses due to lateral movement by mechanical drag or dissolution. The exact combinations of these processes and Na accumulation were strongly related to the soil position in the landscape.
\end{abstract}

Index terms: pedogenesis, Bt planic horizon, micromorphology, biotite weathering.

\section{INTRODUÇÃO}

A área de ocorrência dos Planossolos assume, na região do Agreste de Pernambuco, grande importância econômica, tanto pela sua magnitude de ocupação, compreendendo aproximadamente $5.743,2 \mathrm{~km}^{2}$, que corresponde a $5,78 \%$ do total da área do Estado, quanto pela sua utilização intensiva, especialmente com atividades agropecuárias (Silva et al., 2001). Embora possuam, na maioria, condições de fertilidade natural de razoáveis a boas, apresentam fortes limitações ao uso agrícola, sobretudo no que diz respeito às condições físicas e à suscetibilidade à erosão.

O manejo adequado dos solos é possível quando há considerável conhecimento da dinâmica que controla a sua origem e evolução, ou seja, da pedogênese. O reconhecimento dos processos envolvidos na pedogênese é muitas vezes necessário para entender a variabilidade espacial dos solos na paisagem e entender o seu comportamento. A pedogênese dos Planossolos é pouco discutida, especialmente na região em estudo, havendo dúvidas relativas a alguns dos seus aspectos, citados nos levantamentos regionais, por exemplo, o realizado por Jacomine et al. (1973). Aspectos como dualidade ou retrabalhamento do material de origem, natureza dos processos envolvidos na formação das marcantes diferenciações texturais e nas concentrações de $\mathrm{Na}$ e de sais, bem como o entendimento das associações com outros solos, especialmente Neossolos Regolíticos (bem típicas do Agreste Nordestino), são pontos importantes a serem esclarecidos. Essas questões foram referidas também por Jacomine et al. (1973, 1989), Rolim Neto (1991) e Oliveira Neto (1992). Como hipótese deste trabalho, acredita-se que a diferenciação textural desses solos se deva ao processo de formação e acumulação de argila in situ, no horizonte Bt, da própria rocha do local, associado à perda lateral de materiais mais finos do horizonte superficial.

Este trabalho teve como objetivo avaliar a influência do relevo no processo de pedogênese em Planossolos no Agreste Pernambucano, com base nos resultados das análises físicas, químicas, mineralógicas, macromorfológicas e, especialmente, micromorfológicas.

\section{MATERIAL E MÉTODOS}

Foram abertas três trincheiras numa topossequência para descrição macromorfológica dos perfis e coletas de amostras de solos classificados como Planossolos (Jacomine et al., 1973), em área localizada no sítio Ipueiras, que fica no município de São Caetano, a 18,6 km do entrocamento (viaduto) da PE232 com a BR-423, que dá acesso ao município de Cachoeirinha, na região do Agreste do Estado de Pernambuco (Figura 1). Essa região é caracterizada por apresentar clima semiárido, muito quente; segundo Köppen, corresponde a um domínio de BSs'h'. A estação chuvosa adianta-se para outubro, antes do inverno. A temperatura média anual varia de 22 a $24^{\circ} \mathrm{C}$. A precipitação pluvial média anual predominante na área varia de 600 a $800 \mathrm{~mm}$, com cinco a oito meses secos, além de irregularidades de chuvas (Jacomine et al., 1973). A região do Agreste está situada no Planalto da Borborema, que constitui o mais elevado bloco contínuo do Nordeste brasileiro, e apresenta uma parte com predomínio de relevo suave ondulado, com altitudes de 300 a $600 \mathrm{~m}$. 

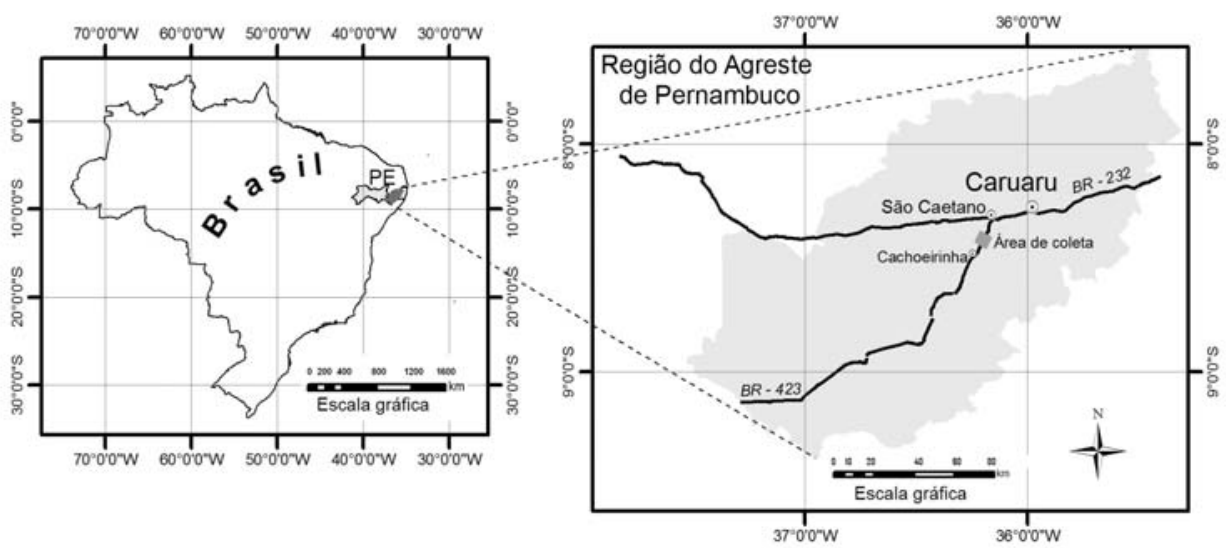

Figura 1. Localização da área de estudo.

O substrato geológico é constituído por rochas do cristalino do período do Pré-Cambriano, formado predominantemente pelo Complexo Migmatíticogranitoide (Lins, 1989). Especificamente, no local de coleta dos perfis de solos, o substrato geológico é biotita gnaisse. Os três perfis ocuparam diferentes posições na topossequência em uma encosta longa de $1 \mathrm{~km}$ (Figura 2), com declividade média de $8 \%$ : o perfil 1 na parte superior de encosta; o perfil 2 , no terço médio; e o perfil 3, no terço inferior de encosta. Os perfis possuem as seguintes coordenadas geográficas: perfil 1 - 24L 806827 UTM 9064135; perfil 2 - 24L 0806810 UTM 9064091; e perfil 3 - 24L 0806779 UTM 9064010. A altitude média está em torno dos $563 \mathrm{~m}$.

Coletaram-se amostras deformadas de todos os horizontes para análises físicas, químicas e mineralógicas. Os perfis de solos foram descritos de acordo com Santos et al. (2005), com a nomenclatura de horizontes, segundo as normas da Embrapa (1988a,b) e utilizando os critérios do Sistema Brasileiro de Classificação de Solos (Embrapa, 2006).

Foram determinadas a composição granulométrica (método do densímetro), densidade do solo (método do torrão parafinado) e densidade de partículas (balão volumétrico) e calculada a porosidade total - todos métodos-padrão utilizados do Manual de Métodos de Análise do Solo (Embrapa, 1997).

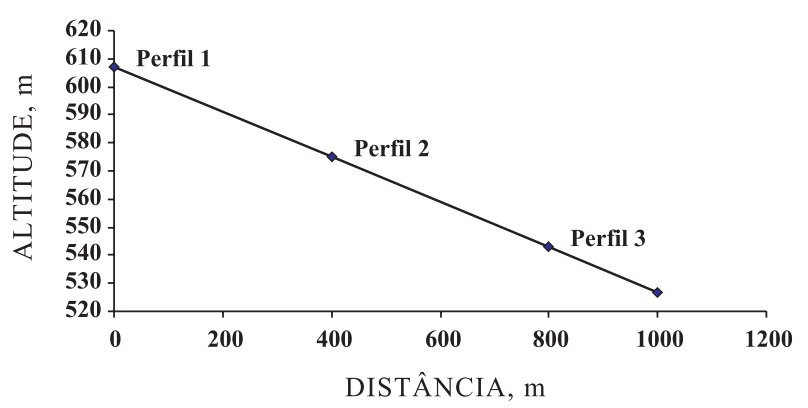

Figura 2. Situação dos perfis em relação à declividade e altitude.
Para caracterização química, foram realizadas as análises do $\mathrm{pH}$ em água e em $\mathrm{KCl}, \mathrm{Ca}^{2+}, \mathrm{Mg}^{2+}, \mathrm{K}^{+}$, $\mathrm{Na}^{+}$e $\mathrm{Al}^{3+}$, usadas para classificação de solos. Determinou-se a condutividade elétrica do extrato de saturação dos solos, empregando-se o condutivímetro. Todos os métodos utilizados nas análises supracitadas foram os recomendados pela Embrapa (1997).

Análises mineralógicas das frações silte e argila foram realizadas pela técnica de difração de raios X. Após a separação da fração argila na determinação granulométrica, efetuou-se a desferrificação, os tratamentos com saturação com $\mathrm{Mg}$ e glicerol e com $\mathrm{K}$, em temperatura ambiente e aquecidas a $550^{\circ} \mathrm{C}$ por duas horas e a preparação de lâminas com orientação paralela (Jackson, 1979). Na fração silte, as lâminas foram confeccionadas com pó de silte natural (sem tratamento) e colocadas em resina nas lâminas, para posterior análise de raios X. Foram obtidos difratogramas para cada tratamento, utilizando-se equipamento de difração de raios $\mathrm{X}$ Rigaku com radiação $\mathrm{CuK} \alpha$. A classificação dos minerais foi realizada em nível de grupo, com base nos espaçamentos basais característicos, segundo Grim (1968), Dixon \& Weed (1989) e Resende et al. (2005). A mineralogia das frações mais grosseiras foi obtida por meio da identificação das características óticas dos minerais, analisadas em lâminas delgadas com o microscópio petrográfico.

Para os estudos micromorfológicos coletaram-se amostras (torrões) com estrutura indeformada, posteriormente impregnadas com resina de poliéster sob vácuo, e prepararam-se lâminas delgadas pelo método de Jongerius \& Heintzberger (1963). Na descrição das seções delgadas a terminologia utilizada foi a de Brewer \& Pawluk (1975), Brewer (1976) e Bullock et al. (1985). Os termos em português, quando possível, foram os sugeridos por Lima et al. (1985) e Stoops (1986). As análises quantitativas nas lâminas delgadas foram efetuadas utilizando-se o método de contagem de pontos (Brewer, 1976), sendo contados sempre 3.000 pontos para cada feição quantificada. 


\section{RESULTADOS E DISCUSSÃO}

\section{Características físicas e morfológicas}

A análise das características físicas e morfológicas (Quadros 1 e 2) indica que há pouca variabilidade entre os três perfis da topossequência estudada. As diferenças de profundidade, cor, textura, estrutura, consistência e densidades, comumente associadas ao condicionamento imposto pelo posicionamento dos solos no relevo, são bastante parecidas (Quadro 1). Apesar da contrastante diferenciação textural entre os horizontes Ap e Bt, os solos são basicamente de textura média, com gradiente de argila mais acentuado no perfil 3 da parte mais baixa do relevo e menor na encosta (Quadro 2). O horizonte Bt dos solos estudados atende aos requisitos, do horizonte plânico, de mudança textural abrupta e subjacente ao horizonte A, segundo o Sistema Brasileiro de Classificação de Solos (Embrapa, 2006). Os dados de densidade global nos horizontes Bt confirmam maiores adensamentos correspondentes às mais elevadas concentrações de argila, com consequente queda na porosidade total desses horizontes (Quadro 2). Os valores dos percentuais de porosidade total são inversamente proporcionais aos gradientes de argila.

\section{Características químicas gerais}

As características químicas gerais (Quadro 3) mostram tratar-se de solos com reação moderadamente ácida nos horizontes superficiais e moderadamente alcalina a fortemente alcalina nos horizontes subsuperficiais.

Observa-se que a soma de bases trocáveis nos três perfis apresenta valores altos, tendo como principais contribuintes o $\mathrm{Ca}^{2+}$ e o $\mathrm{Mg}^{2+}$. A presença de altos teores de bases e a baixa acidez trocável condicionam os altos níveis de saturação por bases, conferindo aos solos o caráter eutrófico (Camargo et al., 1987; Embrapa, 1988a). Convém, no entanto, observar que uma considerável parcela dessa saturação deve-se à

Quadro 1. Características morfológicas dos perfis estudados

\begin{tabular}{|c|c|c|c|c|c|c|c|c|}
\hline \multirow{2}{*}{ Horizonte } & \multirow{2}{*}{$\begin{array}{l}\text { Profundi- } \\
\text { dade }\end{array}$} & \multirow{2}{*}{ Cor úmida ${ }^{(1)}$} & \multirow{2}{*}{ Textura $^{(2)}$} & \multirow{2}{*}{ Estrutura $^{(3)}$} & \multicolumn{3}{|c|}{ Consistência $^{(3)}$} & \multirow{2}{*}{ Transição $^{(5)}$} \\
\hline & & & & & Seca & Úmida & Molhada & \\
\hline Ap & $\begin{array}{c}\mathrm{cm} \\
0-12\end{array}$ & $\begin{array}{l}\text { br. acz. mui. esc. } \\
\text { 10YR } 3,5 / 2\end{array}$ & Fr. Ar. & $\begin{array}{l}\text { Perfil } 1 \\
\text { mac. mode. coesa }\end{array}$ & ext. d. & fi. & lig. plás. e peg. & ab. e pl. \\
\hline $\mathrm{Bt}$ & $12-26$ & $\begin{array}{l}\text { br. acz. esc. } \\
\text { 10YR } 4 / 2\end{array}$ & $\begin{array}{l}\text { Fr. Arg. } \\
\text { Ar }\end{array}$ & $\begin{array}{l}\text { for. gr. pr. comp. de mod. } \\
\text { méd. bl. ang. e subang. }\end{array}$ & ext. d. & mui. fi. & plás. e peg. & cl. e pl. \\
\hline Btn & $26-40$ & $\begin{array}{l}\text { br. acz. } \\
2,5 \mathrm{Y} 4,5 / 2\end{array}$ & Arg. Ar. & $\begin{array}{l}\text { mod. gr. pr. comp. de mod. } \\
\text { méd. à gr. bl. ang e subang. }\end{array}$ & ext. d. & mui. fi. & plás. e peg. & cl. e ond. \\
\hline $\mathrm{Cn}$ & $40-53$ & $\begin{array}{l}\text { br. acz. } \\
2,5 \mathrm{Y} 4,5 / 2\end{array}$ & $\begin{array}{l}\text { Fr. Arg. } \\
\text { Ar. }\end{array}$ & fra. méd. bl. ang. e subang. & ext. d. & fi. & plás. e peg. & cl. e ond. \\
\hline Crn & $53-100+$ & $\begin{array}{l}\text { br. acz. } \\
2,5 \text { Y } 5 / 2\end{array}$ & Are. Fr. & D & mui. d. & fria. & - & - \\
\hline Ap & $0-13$ & $\begin{array}{l}\text { br. acz. mui. esc. } \\
\text { 10YR } 3 / 2\end{array}$ & Fr. Ar. & $\begin{array}{l}\text { Perfil } 2 \\
\text { mac. mode. coesa }\end{array}$ & mui. d. & fi. & lig. plás. e lig. peg. & ab. e pl. \\
\hline $\mathrm{Bt}$ & $13-34$ & $\begin{array}{l}\text { br. acz. esc. } \\
10 Y R 4 / 2\end{array}$ & $\begin{array}{l}\text { Fr. Arg. } \\
\text { Ar }\end{array}$ & $\begin{array}{l}\text { for. gr. pr. comp. de mod. méd. } \\
\text { á gr. bl. ang. e subang. }\end{array}$ & mui. d. & mui. fi. & plás. e peg. & cl. e pl. \\
\hline Btn & $34-58$ & $\begin{array}{l}\text { br. am. esc. } \\
\text { 10YR } 4 / 4\end{array}$ & $\begin{array}{l}\text { Fr. Arg. } \\
\text { Ar }\end{array}$ & $\begin{array}{l}\text { fra. à mod.. méd. á gr. } \\
\text { bl. ang. e subang. }\end{array}$ & ext. d. & mui. fi. & plás. e peg. & grad. e pl. \\
\hline $\mathrm{Cn}$ & $58-92$ & $\begin{array}{l}\text { br. am. esc. } \\
\text { 10YR } 4 / 4\end{array}$ & $\begin{array}{l}\text { Fr. Arg. } \\
\text { Ar }\end{array}$ & $\begin{array}{l}\text { fra. méd. à gr. bl. } \\
\text { ang. e subang. }\end{array}$ & mui. d. & mui. fi. & lig. plás. e peg. & cl. e ond. \\
\hline Crnz & $92-120+$ & $\begin{array}{l}\text { br. acz. esc. } \\
2,5 \text { Y0R } 4 / 2\end{array}$ & Fr. Ar & - & mui. d. & fria. & & - \\
\hline Ap & $0-13$ & $\begin{array}{l}\text { br. acz. mui. esc. } \\
\text { 10YR } 3,5 / 2\end{array}$ & Fr. Ar. & $\begin{array}{l}\text { Perfil } 3 \\
\text { mac. mode. coesa }\end{array}$ & mui. d. & fi. & lig. plás. e lig. peg. & ab. e pl. \\
\hline $\mathrm{Bt}$ & $13-30$ & $\begin{array}{l}\text { br. acz. esc. } \\
\text { 10YR } 4 / 2\end{array}$ & $\begin{array}{l}\text { Fr. Arg. } \\
\text { Ar. }\end{array}$ & $\begin{array}{l}\text { for. gr. pr. comp. de mod. } \\
\text { méd. bl. ang. e subang. }\end{array}$ & ext. d. & mui. fi. & plás e peg. & cl. e pl. \\
\hline Btn & $30-42$ & $\begin{array}{l}\text { br. acz. mui. esc. } \\
2,5 \mathrm{Y} 3 / 2\end{array}$ & Fr. Argi. & fra. méd. bl. ang. e subang. & ext. d. & mui. fi. & plás. e peg. & cl. e pl. \\
\hline Crnz & $42-100+$ & $\begin{array}{l}\text { br. acz. mui. esc. } \\
2,5 \mathrm{Y} 4 / 2\end{array}$ & Fr. Ar. & - & ext. d. & fria. & - & - \\
\hline
\end{tabular}

(1) br.: bruno; acz.: acinzentado; esc.: escuro; am.: amarelado. ${ }^{(2)}$ Fr.: franco; Ar.: arenosa; Arg.: argilo; Ar.: areia; Argi.: argilosa. (3) mac.: maciça; mode.: moderadamente; gr.: grande; pr.: prismática; mod.: moderado; for.: forte; fra.: fraca; méd.: média; bl.: blocos; ang.: angulares; subang.: subangulares. ${ }^{(4)}$ ext.: extremamente; mui.: muito; plás.: plástica; lig.: ligeiramente; fria.: friável; peg.: pegajosa. ${ }^{(5)}$ pl.: plana; ab.: abrupta; cl.: clara; ond.: ondulada; grad.: gradual. 
Quadro 2. Características físicas dos perfis estudados

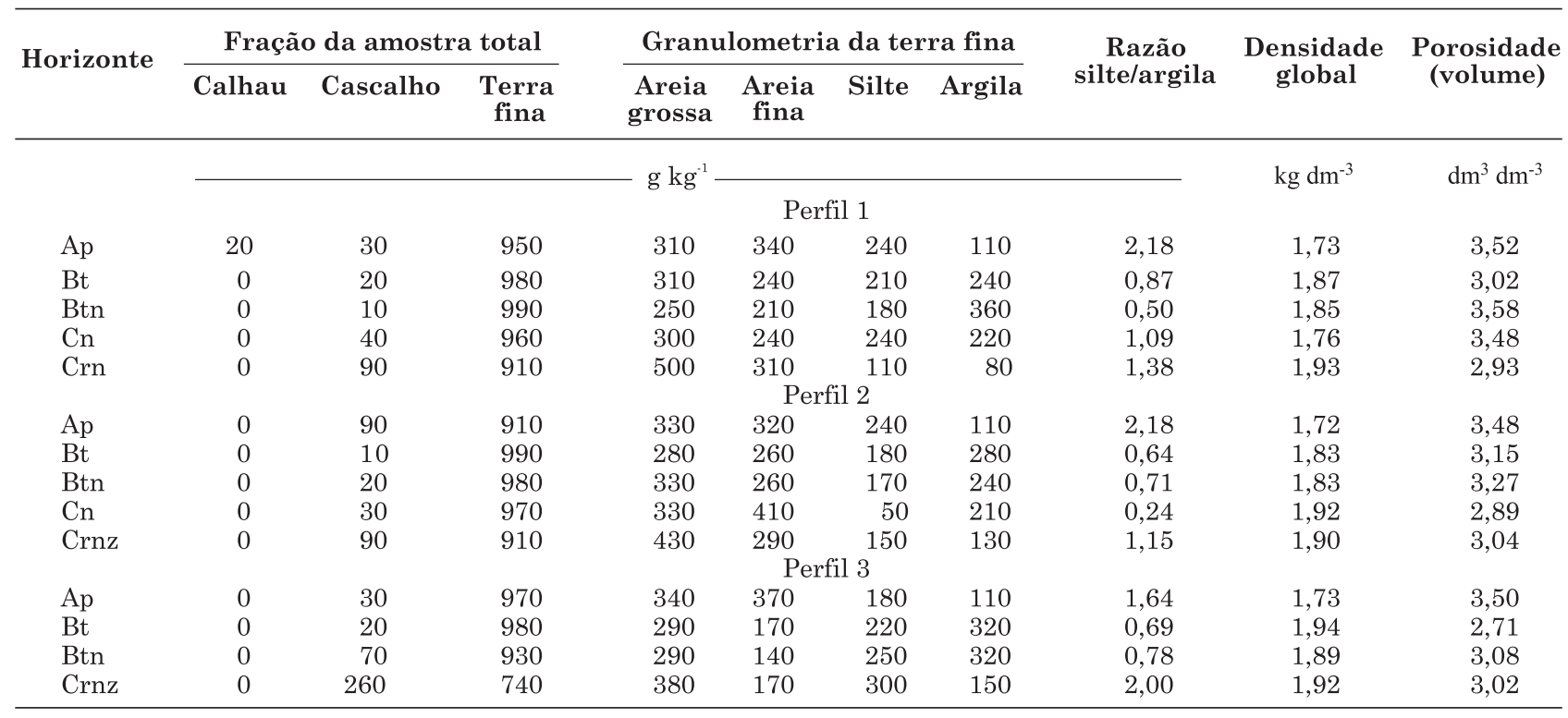

Quadro 3. Características químicas dos perfis estudados

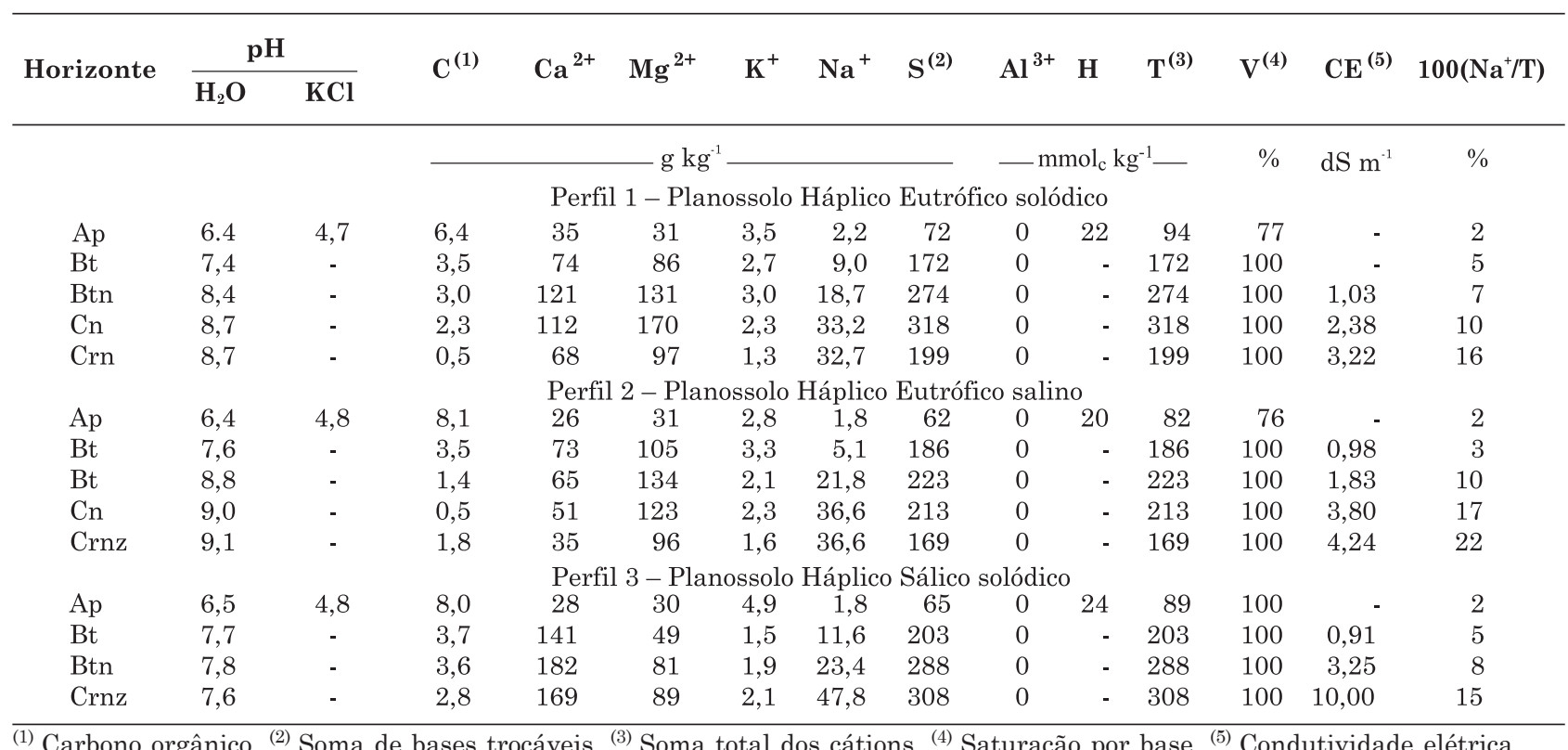

presença do $\mathrm{Na}$, que ocorre em valores entre 7 e $10 \%$ da saturação nos perfis 1, 2 e 3. Esses valores conferem aos solos o caráter solódico, segundo o Sistema Brasileiro de Classificação de Solos (Embrapa, 2006). A atividade da argila é alta nos três perfis, estimada pela capacidade de troca catiônica (após correção da contribuição da matéria orgânica), com valores bem superiores a $240 \mathrm{mmol}_{\mathrm{c}} \mathrm{kg}^{-1}$ de solo em todos os horizontes. Os teores de $\mathrm{C}$ são baixos, como esperado para as condições semiáridas da região.
Consideráveis teores de sais são registrados nos três perfis, por meio da condutividade elétrica do extrato de saturação, aumentando na direção das partes mais baixas do relevo (perfis 2 e 3 ). Verifica-se, pelas características químicas gerais, que as maiores distinções entre os três perfis estão relacionadas às concentrações de sais prontamente solúveis e aos níveis de $\mathrm{Na}$ no complexo sortivo dos horizontes mais profundos. Além de outros fatores, como clima e material de origem, esses fatos são decorrentes do relevo geral 
da área, que é do tipo suave ondulado e plano, especialmente de abaciamentos subsuperficiais. De acordo com Embrapa (2006), os perfis 2 e 3 caracterizam-se, respectivamente, como salino e sálico (Quadro 3). O $\mathrm{pH}$ mais baixo nos horizontes subsuperficiais do perfil 3 , de maneira geral, está associado às saturações por $\mathrm{Na}$, menores que as registradas nos horizontes similares dos outros dois perfis.

\section{Mineralogia da fração grosseira (calhau, casca- lho e areia)}

A mineralogia das frações maiores que o silte, analisada tanto com o auxílio de lupa nos separados maiores que $0,05 \mathrm{~mm}$, quanto com o microscópio petrográfico nas lâminas delgadas, indica grande homogeneidade nos três perfis. Essa homogeneidade foi constatada em termos qualitativos e semiquantitativos e no grau de intemperização, quando comparados horizontes similares. Quartzo, micas e feldspatos são os principais minerais que constituem as frações grosseiras, ocorrendo algum anfibólio e traços de zircão, turmalina, rutilo, epidoto e piroxênios. A maior parte das micas é constituída por biotita, apresentando considerável grau de intemperização, mesmo nos horizontes Crn, onde ocorre também alguma muscovita. Dos feldspatos, há predominância dos plagioclásios e de pequenas quantidades de microclinas.

\section{Mineralogia das frações silte e argila}

A mineralogia da fração silte dos três perfis estudados, determinada por difratometria de raios $\mathrm{X}$, é pouco variável, sendo representada principalmente pela presença de quartzo e feldspatos (Figura 3). Outros minerais ocorrem em espaçamentos de difração maiores que $1,2 \mathrm{~nm}$, indicando serem expansíveis, mas, devido à não execução de tratamentos térmicos ou saturação por $\mathrm{K} \mathrm{e} \mathrm{Mg}$, não puderam ser confirmados.

É interessante observar a total ausência de micas na fração silte, mesmo nos horizontes mais profundos e menos intemperizados, embora seja um mineral, como observado pela mineralogia ótica, presente em grandes quantidades, especialmente a biotita. A instabilidade da biotita e a sua transformação direta em argilominerais expansivos tipo 2:1 têm sido observadas por diversos autores, como Fanning et al. (1989). Essa instabilidade depende da natureza do mineral, do tamanho das partículas e das condições ambientais. Esses autores afirmam que a biotita é mais instável em ambientes de redução que de oxidação, sendo o mecanismo de transformação associado à substituição de K por cátions hidratados.

A mineralogia da fração argila dos três perfis estudados, também determinada por difratometria de raios X, é bastante semelhante. Podem ser observados (Figura 4), por meio do perfil 3, os minerais dominantes. Observou-se ainda a presença de algum quartzo e feldspatos, provavelmente constituindo a subfração argila grossa.
A presença de esmectita é bastante nítida com intensidades em torno de $1,7 \mathrm{~nm}$ nas amostras saturadas com Mg e solvatadas com glicerol. Essas intensidades diminuem para espaçamentos de difração em torno de 1,2 $\mathrm{nm}$ quando a amostra é saturada com Ke para $0,98 \mathrm{~nm}$ quando aquecida a $550{ }^{\circ} \mathrm{C}$. Observase que, nos três perfis, as intensidades das esmectitas diminuem de nitidez e tamanho na direção dos horizontes mais superficiais (Figura 4). Há também pequenas intensidades indicativas do mineral caulinita, apresentando mesma tendência de diminuição na direção dos horizontes mais intemperizados, sendo praticamente ausentes no horizonte Ap. A tendência de comportamento similar das esmectitas e caulinitas é mais indicativa de que há perdas desses minerais de argila do que uma possível transformação das esmectitas em caulinitas.

$\mathrm{O}$ ambiente de drenagem deficiente, típico desses solos, favorece a pouca transformação das esmectitas (Borchardt, 1989). No perfil 3, os difratogramas das amostras saturadas por $\mathrm{Mg}$ e solvatadas com glicerol apresentaram pequenas intensidades nos espaçamentos de difração de $1,4 \mathrm{~nm}$, que diminuíram para 1,0 nm quando saturadas com K, provavelmente devido à presença de alguma vermiculita (Figura 4). Como observado no comportamento dos outros dois minerais supracitados, também a vermiculita mostra tendência de aumento na direção dos horizontes subsuperficiais, podendo ser um produto intermediário

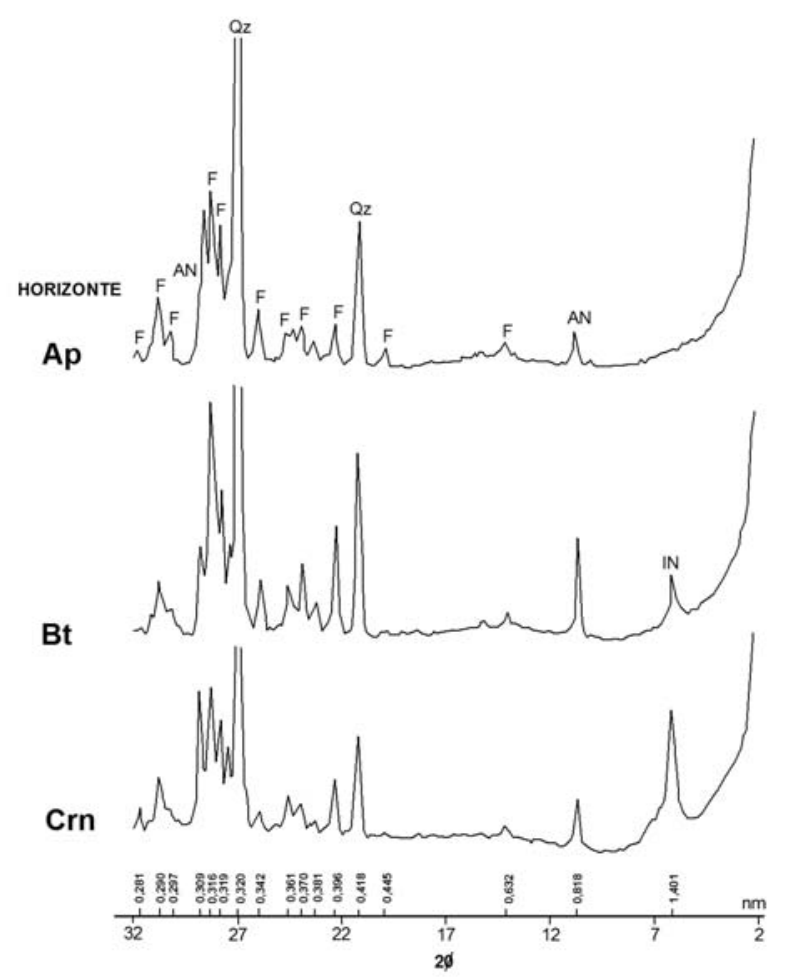

Figura 3. Difratograma de raios $\mathrm{X}$ da fração silte do perfil 3, Planossolo Háplico Sálico solódico. F: feldspato; AN: anfibólio; Qz: Quartzo; IN: interestratificado. 


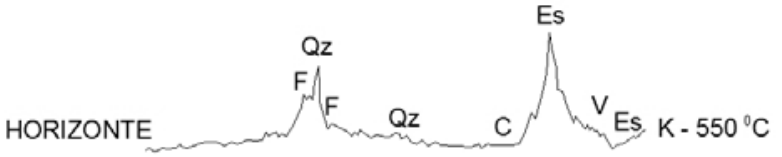

A
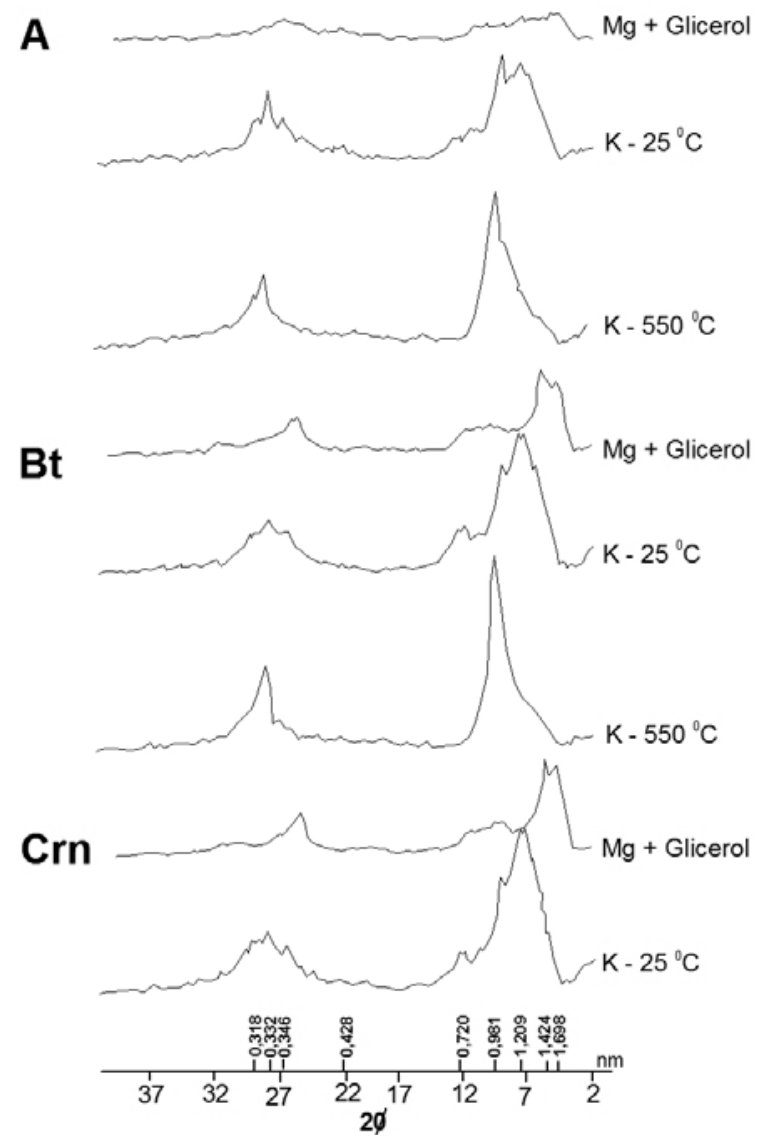

Figura 4. Difratograma de raios X da fração argila do perfil 3, Planossolo Háplico Sálico solódico. C: caulinita; F: feldspato; Qz: quartzo; Es: esmectita; V: vermiculita.

na transformação das micas em esmectitas. Segundo Douglas (1989), a vermiculita, com raríssimas exceções, forma-se quase sempre a partir do intemperismo das micas, em ambiente com baixo fluxo lixiviante e maior presença de Mg no sistema.

\section{Micromorfologia e Pedogênese}

Os três perfis apresentaram características micromorfológicas semelhantes entre os horizontes homólogos. Nos horizontes Ap, a organização dos constituintes matriciais caracterizou-se por uma distribuição das frações grosseiras (areia e cascalho) ao acaso, sendo predominantemente embebidas em um plasma de coloração castanha bastante escura, devido à complexação com matéria orgânica. Áreas de plasma com nuanças alaranjadas representam maiores concentrações de Fe. A grande quantidade de poros do tipo cavidades, predominantemente interconectados, confere aos solos (devido aos seus formatos, tamanhos e arrajamentos) uma aparência geral de que foram formados por coalescência de unidades. Esse tipo de organização matricial enquadrase perfeitamente na contextura intergradiente granóidica porfirosquélica de Brewer \& Pawluk (1975) e leva à formação de uma microestrutura em blocos subangulares consideravelmente desenvolvida. Observa-se que no nível macroscópico foi descrita a condição maciça. Foram constatadas, ainda nos horizontes Ap, separações do plasma em torno de poros e grãos do esqueleto, caracterizando um arranjamento do tipo esquelvossépico fracamente desenvolvido. Verificou-se a presença de pontuações ou pequenos feixes (na granulometria do silte) de material com manifestação de anisotropia ótica, semelhantes a domínios de argila. Esses feixes ou domínios de argila são restos de biotita, parcial ou totalmente intemperizados, promovendo a formação in situ de argilas. Em algumas áreas das lâminas, esses domínios estão ao lado de grãos e poros, tornando, de certa forma, duvidosa a interpretação das separações do plasma descritas. Grande quantidade de restos de raízes, em vários graus de decomposição, alguns carvões e nódulos ferruginosos com limites bem pronunciados ou difusos (granulometria da areia fina) são comuns nos horizontes superficiais dos três perfis.

Os horizontes Bt mostraram-se mais adensados, com maior quantidade de argila e diminuição da macroporosidade. A organização dos constituintes matriciais apresentou os grãos do esqueleto completamente embebidos em um plasma mais claro e homogêneo que o dos horizontes superficiais (Figura 5); compreende, dessa forma, a contextura matricial porfirosquélica de Brewer \& Pawluk (1975). As separações do plasma são marcantes e do tipo esquelvomassépica, ou seja, em volta de grãos e poros e na matriz do solo (Figura 6).

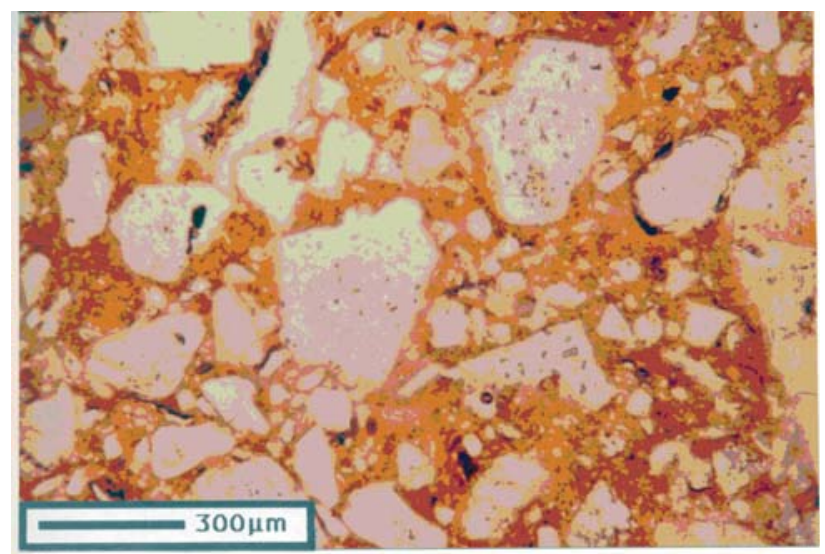

Figura 5. Micrografia do horizonte Bt do perfil 2 em plano polarizado (PPL). Frações grosseiras totalmente embebidas em um plasma bastante homogêneo. 


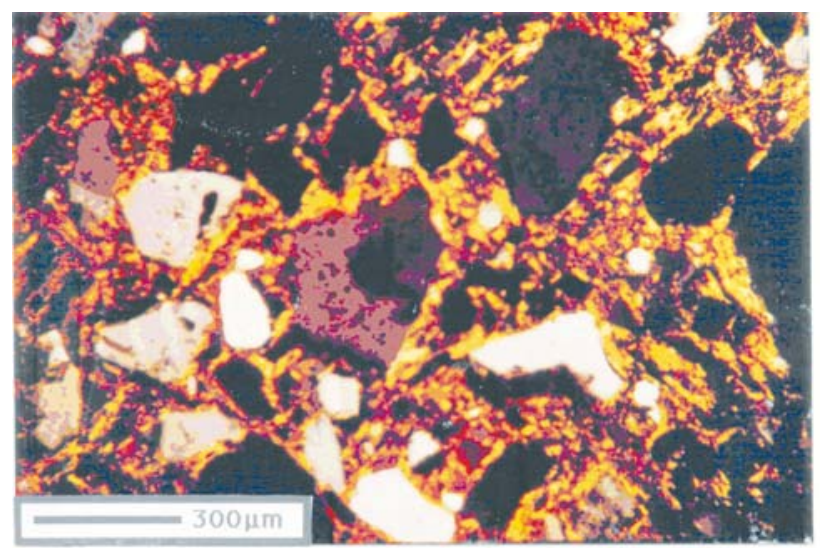

Figura 6. Mesma micrografia da figura 5, tirada com nicóis cruzados.Verifica-se a separação do plasma em volta de grão e poro e na matriz do solo.

A expressão de ocorrência das pontuações e, predominantemente, dos feixes de argilas provenientes da intemperização in situ das biotitas, como descrito para os horizontes Ap, é bem mais marcante (Figura 7).

A possibilidade de esses domínios e, ou, separações serem, em sua maioria, decorrentes da intemperização dificulta a interpretação de argilãs como resultantes de iluviação. Na realidade, os argilãs de canais, que representam a expressão máxima de um processo de iluviação de argilas, inexistem nesses horizontes Bt. Há também a possibilidade de ter havido destruição de argilãs devido à movimentação das argilas de atividade alta nesses solos. Constata-se, no entanto, na matriz dos solos, a ausência de pápulas que comumente se formam por destruição dos enchimentos de canais com argila iluvial (Rossignol, 1985). A feição

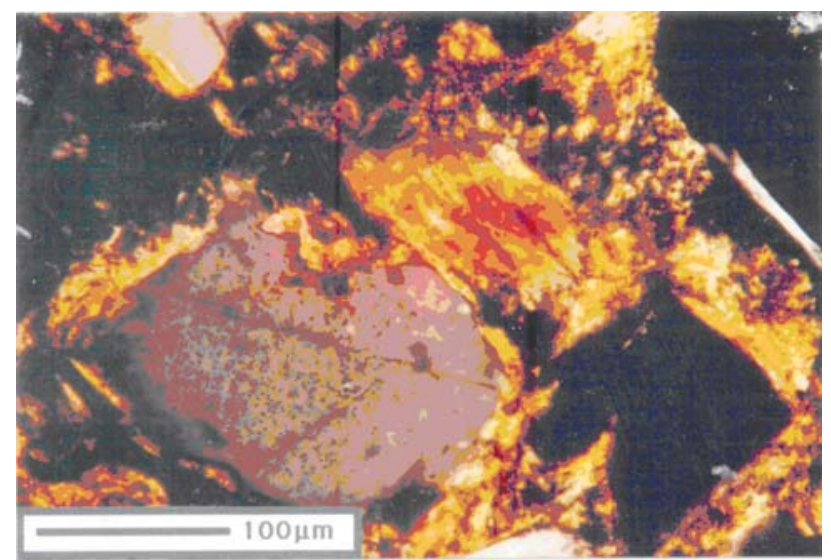

Figura 7. Mesma micrografia do horizonte Bt do perfil 2 com nicóis cruzados. Observam-se argilãs provenientes da intemperização in situ das biotitas circundando um grão de quartzo e a presença de pseudomorfo de biotita. micromorfológica constatada nos solos estudados, que se assemelha a pápulas, tem contextura interna bem peculiar, tratando-se de pseudomorfos de biotita. Esses fatos conduzem à hipótese de que as marcantes diferenças entre os teores de argila dos horizontes Ap e Bt devem ser, ao menos predominantemente, fruto de perdas superficiais de argilas por outros meios que não a eluviação para os horizontes Bt. Mota \& Oliveira (1999) verificaram que o enriquecimento de argila no Bt de dois Planossolos - um em clima semiárido e o outro em subúmido transicional para semiárido resultou essencialmente de alteração in situ dos minerais primários (horblendas, plagioclásios e biotitas).

Não foram observadas características micromorfológicas que dessem suporte ao processo de ferrólise. Dessa forma, a grande maioria dos marcantes argilãs presentes, com forte manifestação de anisotropia ótica, devem ser mais provavelmente os chamados argilãs de intemperização, como denominados por Mermut \& Pape (1971, 1973). A micrografia da figura 7 evidencia a presença de argilãs de intemperização ao lado de poros e grãos, onde se percebe claramente a formação in situ de argila e a liberação de Fe.

Não foi constatada a presença de nódulos de Fe com limites pronunciados, mas apenas concentrações com limites bastante difusos e provenientes da liberação de Fe durante a intemperização de minerais primários, especialmente da biotita. Esse fato, de certa forma, corrobora o caráter autóctone do material de origem desses solos.

Nos horizontes Crn, a mais marcante característica observada é a intemperização dos minerais primários, sobretudo da biotita. Fragmentos de biotita (Figura 8) apresentam-se em diversos estádios de intemperização, que se caracterizam por: fragmentação inicial ao longo da clivagem basal; liberação de Fe; e imediata formação de argilas. Essas observações confirmam a passagem direta das micas para os argilominerais, como indicado pela difratometria de raios $\mathrm{X}$ anteriormente discutida. O padrão de distribuição das argilas formadas, com relação à manifestação de anisotropia ótica e cor, é idêntico ao verificado nas separações plásmicas dos horizontes Bt, corroborando a hipótese de formação in situ, predominantemente a iluviação (Figura 8).

A marcante diferença textural, típica dos Planossolos, quase sempre sugere haver influência de mais de um material de origem na sua formação, o que não é o caso dos solos deste estudo, ou que, pelo menos, a parte superficial do solo tenha sido influenciada por um possível retrabalhamento do seu material de origem via ciclos de erosão-transportedeposição, característicos de regiões semiáridas.

Parahyba et al. (2009) verificaram, por meio da pedogênese quantitativa, nesses mesmos perfis de solos, em termos de perdas e ganhos, que os três perfis apresentaram durante o processo evolutivo perdas totais pouco divergentes. Esse fato é corroborado pelas 


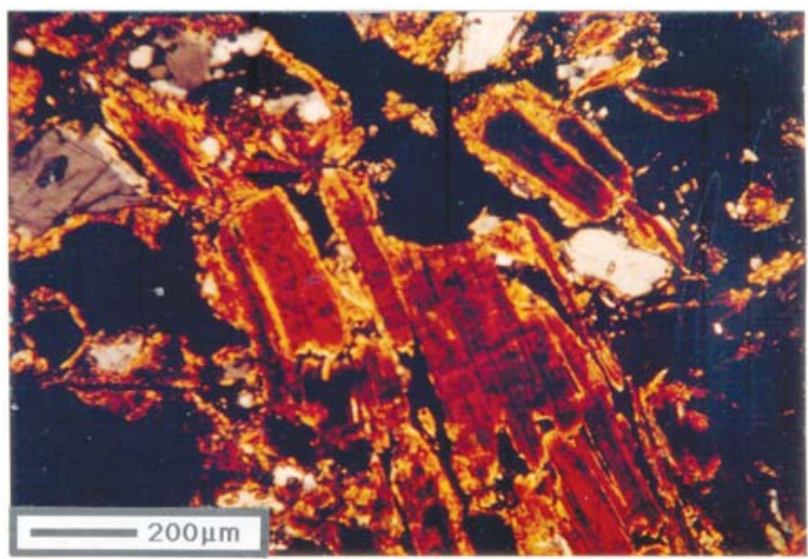

Figura 8. Micrografia do horizonte Crn do perfil 3 com nicois cruzados. Diversos estádios de intemperização de biotitas com produção de argilas. Muitos dos feixes de argila formados são similares aos encontrados nos horizontes superiores.

análises dos dados micromorfológicos, químicos e mineralógicos, comentados anteriormente neste trabalho.

Ainda segundo Parahyba et al. (2009), a diferenciação textural em Planossolos pode não ser decorrente da iluviação de argila, sendo o fator preponderante a intemperização de silte e areia. Esse fato é confirmado neste trabalho pelas observações micromorfológicas, que evidenciam a intemperização de biotitas e produção in situ de argila.

\section{CONCLUSÕES}

1. Os materiais de origem dos três perfis estudados foram considerados autóctones.

2. As marcantes diferenciações texturais nos perfis foram consideradas resultantes de processos relativos à formação in situ de argila por meio da intemperização, especialmente das biotitas. Eluviaçãoiluviação e lessivagem em sentido restrito pareceram exercer menos influência, havendo poucas evidências de terem ocorrido.

3. A mineralogia dos três perfis apresentou-se bastante similar em termos qualitativos, semiquantitativos e no grau de intemperização dos minerais. Esmectitas, principalmente, e caulinita constituem a fração argila, tendo sido formadas predominantemente a partir da intemperização direta de fragmentos grosseiros da biotita.

4. Constatou-se que, de maneira geral, o posicionamento no relevo promoveu poucas diferenciações entre os três perfis, exercendo apenas influência na combinação dos processos causadores das diferenciações texturais e distribuíção do $\mathrm{Na}$.
5. De acordo com a micromorfologia, as principais pedofeições observadas estão relacionadas ao intemperismo dos minerais primários, notadamente a biotita, e à reorganização da massa do solo, em função da mudança da umidade do solo em decorrência das alternâncias entre períodos secos e chuvosos.

6. A presença dos minerais (biotita e plagioclásios) considerados de fácil decomposição nas frações areia e silte dos perfis estudados indica pequeno grau de intemperismo e, ou, maturidade dos solos estudados.

\section{LITERATURA CITADA}

BORCHARDT, G. Smectites. In: DIXON, J.B. \& WEED, S.B., eds. Mineral in soil environment. 2.ed. Madison, Soil Science Society of America, 1989. p.675-728.

BREWER, R. Fabric and mineral analysis of soil. New York, Robert E. Krieger Publishing, 1976. 482p.

BREWER, R. \& PAWLUK, S. Investigations of some soils developed in Hummocks of the Canadian sub-artic and southern-artic regions. 1. Morphology and micromorphology. Canadian J. Soil Sci., 55:301-319, 1975.

BULLOCK, P.; FEDOROFF, N.; JONGERIUS, A.; STOOPS, G. \& TURSINA, T. Handbook for soil thin section description. Albrington, Reino Unido, Waine Research, 1985. $152 \mathrm{p}$.

CAMARGO, M.N.; KLAMT, E. \& KAUFFMAN, J.H. Classificação de solos usada em levantamentos pedológicos no Brasil. B. Inf. SBCS, 12:11-33, 1987.

DIXON, J.B. \& WEED, S.B. Minerals in soil environments. 2.ed. Madison, Soil Science Society of America Published, 1989. $1224 \mathrm{p}$.

DOUGLAS, L.A. Vermiculites. In: DIXON, J. B. \& WEED, S. B., eds. Mineral in soil environments. Madison, Soil Science Society of America, 1989. p. 635-674.

EMPRESA BRASILEIRA DE PESQUISA AGROPECUARIA EMBRAPA. Serviço Nacional de Levantamento e Conservação de Solos. Critérios para distinção de classes de solos e de fases de unidades de mapeamento; normas em uso pelo SNLCS. Rio de Janeiro, 1988a. 67p. (Documentos SNLCS, 11)

EMPRESA BRASILEIRA DE PESQUISA AGROPECUARIA EMBRAPA. Serviço Nacional de Levantamento e Conservação de Solos. Definição e notação de horizontes e camadas do solo. 2.ed. Rio de Janeiro, 1988b. 54p. (Documentos SNLCS, 3)

EMPRESA BRASILEIRA DE PESQUISA AGROPECUARIA EMBRAPA. Centro Nacional de Pesquisa de Solos. Manual de métodos de análises de solo. 2.ed. Rio de Janeiro, 1997. 212p.

EMPRESA BRASILEIRA DE PESQUISA AGROPECUARIA EMBRAPA. Centro Nacional de Pesquisa de Solos. Sistema brasileiro de classificação de solos. Rio de Janeiro, 2006. 306p. 
F.A.O. - UNESCO. Soil map of the world. Roma, 1988. 109p.

FANNING, D.S.; KERAMIDAS, V.Z. \& EL-DESOKY, M.A. Micas. In: DIXON, J.B. \& WEED, S.B., eds. Mineral in soil environment. 2.ed. Madison, Soil Science Society of America, 1989. p.551-624.

GRIM, R.E. Clay mineralogy. 2.ed. New York, McGraw-Hill, 1968. 596p.

JACOMINE, P.K.T.; OLIVEIRA, L.B. \& CAVALCANTI, A.C. Guia de Excursão do Congresso de Ciência do Solo, 22. Recife, SBCS/Embrapa SNLCS, 1989. 72p.

JACOMINE, P.K.T.; CAVALCANTI, A.C.; BURGOS, N.; PESSOA, S.C.P. \& SILVEIRA, C.O. Levantamento exploratório-reconhecimento de solos do Estado de Pernambuco. Recife, DNPEA, Divisão de Pesquisa Pedológica. SUDENE/DRN, Divisão de Agrologia, 1973. v.1. (Boletim técnico, 26 - Série Pedologia, 14)

JACKSON, N.L. Soil chemical analyses - Advanced course. 3.ed. Madison, University of Wisconsin, 1979. 896p.

JONGERIUS, A. \& HEINTZBERGER, G. The preparation of mammoth-sized thin sections. Wageningen, Soil Survey, The Soil Survey Institute, 1963. p.3-37. (Papers, 1)

LIMA, P.C.; CURI, N. \& LEPSCH, I. Terminologia de micromorfologia do solo. B. Inf. SBCS, 10:33-43, 1985.

LINS, R.C. Áreas de exceção do Agreste de Pernambuco. Recife, SUDENE, 1989. 327p.

MERMUT, A.R. \& PAPE, Th. Micromorphology of two soils from Turkey, with special reference to in situ formation of clay cutans. Geoderma, 5:271-281, 1971.

MERMUT, A.R. \& PAPE, Th. Micromorphology of in situ formed clay cutans in soils. 3.ed. Leitz Mitteilungen für Wissenschaft Tchnik, 8:243-246, 1973.
MOTA, F.O.B. \& OLIVEIRA, J.B. Mineralogia de solos com excesso de sódio no Estado do Ceará. R. Bras. Ci. Solo, 23:799-806, 1999.

OLIVEIRA NETO, M. Pedogênese de uma topossequência no Agreste de Pernambuco. Recife, Universidade Federal Rural de Pernambuco, 1992. 142p. (Tese de Mestrado)

PARAHYBA, R.B.V.; SANTOS, M.C. \& ROLIM NETO, F.C. Evolução quantitativa de Planossolos do Agreste do Estado de Pernambuco. R. Bras. Ci. Solo, 33:991-999, 2009.

RESENDE, M.; CURI, N.; KER, J.C. \& REZENDE, S.B. Mineralogia de solos brasileiros: Interpretação e aplicações. Lavras, Universidade Federal de Lavras, 2005. 192p.

ROLIM NETO, F.C. Gênese de solo arenoso com lamelas no Agreste de Pernambuco. Recife, Universidade Federal Rural de Pernambuco, 1991. 121 p. (Tese de Mestrado)

ROSSIGNOL, J.P. Les planosols du nord de l'Uruguay. Cahiers O.R.S.T.O.M. Série Pedológie, 21:57-58, 1985.

SANTOS, R.D.; LEMOS, R.C.; SANTOS, H.G.; KER, J.C. \& ANJOS, L.H.C. Manual de descrição e coleta de solos no campo. 5.ed. Viçosa, MG, Sociedade Brasileira de Ciência de Solos, 2005. 100p.

SILVA, F.B.R.; SANTOS, J.C.P.; SILVA, A.B.; CAVALCANTI, A.C.; SILVA, F.H.B.B.; BURGOS, N.; PARAHYBA, R.B.V.; OLIVEIRA NETO, M.B.; SOUSA NETO, N.C.; ARAÚJO FILHO, J.C.; LOPES, O.F.; LUZ, L.R.Q.; LEITE, A.P.; SOUZA, L.G.M.C.; SILVA, C.P.; SILVA, M.A.V. \& BARROS, A.H.C. Zoneamento agroecológico do Estado de Pernambuco. Recife, Embrapa Solos - Unidade de Execução de Pesquisa e Desenvolvimento - UEP Recife; Governo do Estado de Pernambuco (Secretaria de Produção Rural e Reforma Agrária), 2001. CD-ROM. (Embrapa Solos. Documentos, 35)

STOOPS, G. Multilingual translation of the terminology used in the "Handbook for Soil Thin Section Description" Pedologie, 36:337-347, 1986. 